\title{
FAKTOR-FAKTOR YANG MEMPENGARUHI KEPUTUSAN PEMBELIAN GULA KRISTAL PUTIH DI DAERAH ISTIMEWA YOGYAKARTA
}

\author{
Ecclisia Sulistyowati ${ }^{1)}$, Tri Wisudawati ${ }^{2)}$, Wahyu Adhi Saputro ${ }^{3)}$ \\ ${ }^{1)}$ Program Studi Manajemen, Fakultas Hukum dan Bisnis, Universtas Duta Bangsa Surakarta, \\ ${ }^{2)}$ Program Studi Teknik Industri, Fakultas Sains dan Teknologi, Universtas Duta Bangsa Surakarta, \\ ${ }^{3)}$ Program Studi Agribisnis, Fakultas Sains dan Teknologi, Universtas Duta Bangsa Surakarta, \\ Jl. Bhayangkara Tipes Serengan Kota Surakarta 57154 telp. (0271) 719552 \\ *email: ecclisia sulistyowati@udb.ac.id ; tri.wisudawati@udb.ac.id ; wahyuadhi@udb.ac.id
}

\begin{abstract}
ABSTRAK
Gula kristal putih berfungsi sebagai sumber energi/kalori bagi tubuh. Permintaan gula kristal putih di Daerah Istimewa Yogyakarta mengalami kenaikan seiring dengan bertambahnya jumlah penduduk. Konsumen memiliki kriteria tersendiri dalam memilih dan mengkonsumsi gula kristal putih. Tujuan dari penelitian ini ialah mengetahui dan menganalisis tentang faktor-faktor apasajakah yang mempengaruhi keputusan pembelian gula kristal putih di DIY. Pendekatan yang digunakan adalah deskriptif kuantitatif dengan populasi semua konsumen gula kristal putih yang berbelanja di mini market dan super market di DIY. Penentuansampling menggunakan purposive sampling. Responden berjumlah sebanyak 40 orang. Analisis data menggunakan analisis regresi berganda. Hasil analisis data penelitian menunjukkan bahwa kualitas produk, harga, kemasan, jaminan produk dan merk secara simultan memberikan pengaruh terhadap keputusan pembelian gula kristal putih di DIY. Variabel yang berpengaruh secara signifikan terhadap keputusan pembelian gula kristal putih adalah kualitas produk, jaminan produk dan merk produk sementara itu variabel harga dan kemasan tidak memberikan pengaruh signifikan terhadap keputusan pembelian.
\end{abstract}

Kata Kunci: Gula; Keputusan; Pembelian

\begin{abstract}
Sugar serves as a source of energy/calories for the body. The demand for sugar in Region of Yogyakarta has increased along with the increasing population. Consumers have their own criteria for choosing and consuming sugar. This study aims to know and analyze about factors that influence the purchase decision of sugar in DIY. The approach used is descriotive quantitive with a population of sugar consumers who shop at mini markets and super markets in DIY. Determination of sampling using purposive sampling. Respondents numbered as many as 40 people. Data analysis used multiple regression analysis. The results showed that simultaneously of product quality, price, packaging, product and brand guarantees has influence to purchased decision of sugar, but separately the quality, product and brand guarantees has influence, while price and packaging has no influence to purchase decision of sugar in DIY.
\end{abstract}

Keywords: Decision, Purchase, Sugar

\section{PENDAHULUAN}

Salah satu dari sembilan bahan pokok yaitu gula berfungsi untuk pemenuhan sumber energi/kalori bagi tubuh. Sumber kalori yang dimaksud lebih utamanya sebagai pemanis. Kebutuhan gula nasional saat ini mencapai 5,01 juta ton per tahuns sehingga dapat dihitung bahwa kebutuhan $15 \mathrm{~kg}$ per tahun per kapita (Toharisman, 2011). Perkembangan harga gula kristal putih di pasar domestik dalam negeri memiliki trend positif pada periode 1997-2014. Peningkatan trend tersebut berkisar $14,15 \%$ setiap tahunnya. Periode tersebut terjadi pula kenaikan harga eceran gula kristal putih di Indonesia hingga mencapai $79,43 \%$ pada tahun 1998 hingga pada tahun 2014 harga gula kristal putih tercatat mencapai Rp10.859 kg 1997 (Direktorat Jenderal Perkebunan, 2015).

Keputusan konsumen dalam membeli produk atau jasa tidak muncul begitu saja akan tetapi melalui tahapan tertentu. Berdasarkan model Engel et al, (1994) 
terdapat lima tahapan proses keputusan pembelian yaitu pengenalan kebutuhan, pencarian informasi, evaluasi alternate, pembelian dan hasil. Konsumen memiliki perasaan puas atau tidak puas setelah mengkonsumsi suatu barang atau jasa. Konsumen yang merasa puas akan terdorong untuk membeli dan mengkonsumsi secara berulang kali dan begitu juga sebaliknya. Kepuasan didefinisikan sebagai rasa senang atau kecewa setelah membandingkan antara kinerja (hasil) produk yang dipikrkan terhadap kinerja yang diharapkan (Kotler, 2005).

Produk merupakan segala sesuatu yang dapat ditawarkan produsen untuk diperhatikan, diminta, dicari, dibeli, digunakan, atau dikonsumsi pasar sebagai pemenuhan kebutuhan atau keinginan pasar yang bersangkutan (Tjiptono, 1995). Kualitas produk yang baik akan membuat kosumen akan membeli produk secara berulang-ulang. Keunggulan yang dimiliki oleh perusahaan selaku penjual produk dan jasa yang memiliki suatu keunggulan tertentu dapat membuat perusahaan tersebut bertahan dalam dunia persaingan (Novitawati dkk, 2019). Rohman (2018) mengatakan bahwa servis terbaik akan memberikan kepuasan bagi konsumen dan menjadi salah satu komponen penting agar perusahaan dapat bertahan di tengah persaingan. Kepuasan yang lebih dapat diberikan kepada konsumen dengan memberikan kualitas pelayanan yang baik sehingga memudahkan perusahaan untuk mencapai tujuan peningkatan jumlah pembeli (Darmawan, 2018). Keunggulan suatu perusahaan juga ditentukan dari lokasi pasar yang strategis, produk yang dijual serta harga dari produk (Susanto, 2017). Sumber daya manusia sebagai tenaga kerja sektor informal sedang dalam masa kekurangan (Gunawan, 2016). Tenaga kerja dalam perusahaan yang semakin handal membuat produk dan jasa keluaraan dari perusahaan akan semakin baik.
Harga merupakan satu-satunya unsur dalam bauran pemasaran yang memberikan income bagi perusahaan (Tjiptono, 2011). Senada dengan hal tersebut Kotler dan Keller, 2008 juga mengatakan bahwa harga adalah salah satu elemen bauran pemasaran yang menghasilkan pendapatan. Sejumlah uang yang ditagihkan dikarenakan pembelian produk atau jasa disebut harga. Harga juga berarti bahwa jumlah dari nilai yang ditukarkan pada pelanggan untuk memperoleh manfaat dari penggunaan suatu produk atau jasa. Menurut Kurniasari (2013) harga mempunyai pengaruh dan pengaruh yang ditimbulkan bersifat positif dan signifikan terhadap keputusan pembelian. Tidak hanya itu tingkat permintaan juga diakibatkan dari harga yang ditimbulkan dari produk dan jasa yang dijual belikam. Pernyataan ini sesuai dengan hukum permintaan dimana semakin tinggi harga maka akan semakin rendah terhadap permintaan produk dan juga sebaliknya. Atas dasar hal tersebut maka penetapan harga yang cocok akan mempengaruhi daya beli konsumen.

Persaingan antar berbagai merk produk gula kristal menjadikan konsumen memiliki berbagai pilihan dalam mengkonsumsi produk gula. Ketatnya persaingan tersebut memaksa perusahaan harus mengembangkan strategi pemasarannya sehinga produknya menjadi familiar dimata konsumen. Strategi yang dapat diterapkan oleh perusahaan untuk mempertahan konsumen dan meperoleh konsumen baru dengan memiliki reputasi baik (Agung et al, 2006). Strategi pemasaran yang tepat harus dimiliki oleh perusahaan dalam menanggapi adanya persaingan pasar yang ketat. Perusahaan yang tidak dapat bertahan menanggulangi hal tersebut dipastikan akan mengalami kerugian (Nasir, 2018). Strategi pemasaran masing-masing perusahaan memiliki peran penting agar tidak collapse dan mengalami kerugian yang besar. Strategi 
pemasaran diperuntukan untuk meningkatkan jumlah penjualan produk sesuai dengan target yang direncanakan (Nasir, 2017). Salah satu strategi pemasaran dapat diwujudkan dengan pengelolaan kualitas layanan yang baik pula sehingga menjadikan daya tarik tersendiri bagi konsumen (Rahareng dan Relawan, 2017). Hal yang penting bagi penjualan produk dan jasa adalah citra atau image perusahaan (Faullant et al., 2008). Apabila konsumen di berikan pilihan beberapa produk yang jika ditinjau dari segi harga tidak memiliki perbedaan jauh maka konsumen cenderung memilih produk dengan merk lebih dikenal konsumen (Aaker, 2011). Banyak hal yang dapat dilakukan untuk memperbaiki pelayanan yang prima kepada konsumen, salah satunya dengan ecaluasi mengenai kepuasan pelayanan (Wisudawati dan Dharmastiti, 2018). Strategi pemasaran perlu dilakukan untuk memasarkan dan mempromosikan produk secara luas dan baik untu menambah profit pelaku usaha (Wisudawati dan Sulistyowati, 2019). Seiring dengan peningkatan konsumsi seiring pula industri berkembang pesat (Kusumowardhani dkk, 2019)

Tingginya konsumsi gula di DIY sebanding dengan peningkatan jumlah penduduk dari tahun ke tahun menyebabkan perlu diketahuinya faktor penentu yang menyebabkan konsumen memutuskan untuk membeli produk yang dijual oleh perusahaan khususnya dalam penelitian ini yaitu produsen gula (PTPN) dalam memikirkan produknya. Perusahaan terutama PTPN perlu mengetahui motif apa saja yang menyebabkan konsumen membeli produk gula kristal putih. Guna mengetahui motif apa saja yang mempengaruhi konsumen dalam menentukan keputusan pembelian akan produk gula kristal putih di Daerah Istimewa Yogyakarta makapeneliti akan menguji faktor-faktor apa saja yang mempengaruhi keputusan pembelian gula kristal putih di Daerah Istimewa Yogyakarta.

\section{METODE PENELITIAN}

Lokasi penelitian ini dilakukan di Daerah Istimewa Yogyakarta. Pemilihan lokasi tersebut secara purposive atau sengaja dengan mempertimbangkan hal tertentu. Teknik penetuan lokasi dengan acuan beberapa pertimbangan disebut dengan metode purposive (Sugiyono, 2012). Daerah Istimewa Yogyakarta dipilih karena lokasi tersebut berdasarkan data dari Badan Pusat Statistik jumlah penduduk mencapai 3,8 juta jiwa pada tahun 2019. Sampel yang diambil sejumlah 40 orang. Menurut teori penarikan sampel dari Walpole (1992) untuk menggunakan analisa statistic ukuran sampel paling minimum 30 responden. Responden dalam penelitian ini adalah konsumen yang berbelanja di beberapa minimarket maupun supermarket di DIY. Penelitian ini terdiri dari dua jenis data yaitu data primer dan data sekunder. Data primer diperoleh dari hasil wawancara secara langsung kepada konsumen gula kristal putih di DIY dengan menggunakan kuesioner. Data sekunder diperoleh dari data instansti terkait seperti Badan Pusat Statistik. Identifikasi masalah faktor-faktor apa saja yang mempengaruhi keputusan pembelian gula kristal putih di Daerah Istimewa Yogyakarta menggunakan metode regresi linear berganda. Nilai parameter tersebut selanjutnya akan di duga sehingga modelnya menjadi :

$$
\mathrm{Y}=\mathrm{a}+\mathrm{b}_{1} \mathrm{X}_{1}+\mathrm{b}_{2} \mathrm{X}_{2}+\mathrm{b}_{3} \mathrm{X}_{3}+\mathrm{b}_{4} \mathrm{X}_{4}+\mathrm{b}_{5} \mathrm{X}_{5}+\mathrm{e}
$$

dimana:

$\mathrm{Y} \quad=$ Keputusan Pembelian

$\mathrm{X}_{1} \quad=$ Kualitas Produk

$\mathrm{X}_{2}=$ Harga

$\mathrm{X}_{3}=$ Kemasan

$\mathrm{X}_{4} \quad=$ Jaminan Produk

$\mathrm{X}_{5} \quad=$ Merk

a $=$ Konstanta

$\mathrm{b}_{1,2,3,4,5}=$ Koefisien regresi

$\mathrm{e} \quad=$ Error 


\section{HASIL DAN PEMBAHASAN}

\section{Faktor-Faktor yang Mempengaruhi Keputusan Pembelian Gula Kristal Putih di DIY}

Faktor-faktor yang mempengaruhi keputusan pembelian gula kristal putih di Daerah Istimewa Yogyakarta dapat diketahui menggunakan analisis regresi linear berganda. Variabel independen terdiri dari beberapa atribut yaitu kualitas produk, harga, kemasan, jaminan produk dan Merk sedangkan variabel dependen adalah keputusan pembelian. Peneliti menggunakan program Statistical Package for Social Science (SPSS) dalam menganalisis regresi linear berganda.

Tabel 1 Hasil Analisis Regresi Berganda Faktor-faktor yang Mempengaruhi Keputusan Pembelian Gula Kristal Putih di DIY

\begin{tabular}{llccc}
\hline No. & Faktor Produksi & Koefisien Regresi & Std.Error & Probability $t$ \\
\hline 1 & Konstanta & $1,51^{* *}$ & 0,621 & 0,019 \\
2 & Kualitas Produk $\left(\mathrm{X}_{1}\right)$ & $0,16^{* *}$ & 0,171 & 0,035 \\
3 & Harga $\left(\mathrm{X}_{2}\right)$ & 0,06 & 0,086 & 0,480 \\
4 & Kemasan $\left(\mathrm{X}_{3}\right)$ & 0,08 & 0,159 & 0,576 \\
5 & Jaminan Produk $\left(\mathrm{X}_{4}\right)$ & 0,15 & 0,088 & 0,076 \\
6 & Merk $\left(\mathrm{X}_{5}\right)$ & $0,48^{* * *}$ & 0,135 & 0,001 \\
\hline & Adjusted $\mathrm{R}^{2}$ & 0,43 & & \\
\hline & F $_{\text {hit }}$ & 5,24 & \\
\hline & Probability $F$ & $0,01^{* *}$ & & \\
\hline
\end{tabular}

Sumber: Analisis Data Primer, 2020

Berdasarkan tabel 1 dapat diketahui dari hasil analisis regresi berganda bahwa nilai koefisien regresi dari konstanta bernilai 1,51 dengan probability-t sebesar 0,019 sehingga signifikan. Nilai koefisien regresi konstanta bernilai 1,51 berarti semua variabel bebas yaitu kualitas produk, harga, kemasan, jaminan produk dan merk mempunyai hubungan yang positif terhadap variabel terikat (keputusan pembelian). Apabila nilai dari masing-masing koefisien regresi variabel bebas yaitu 0,16 untuk kualitas produk, harga memiliki koefisien regresi 0,06 , variabel kemasan memiliki nilai koefisien regresi 0,08 ; variabel jaminan produk memiliki nilai koefisien regresi 0,15 ; variabel merk memiliki nilai koefisien regresi 0,48 dimasukkan ke dalam fungsi regresi secara utuh, maka persamaan dapat ditulis sebagai berikut:

$$
\begin{gathered}
\mathrm{Y}=1,51+0,16 \mathrm{X}_{1}+0,06 \mathrm{X}_{2}+0,08 \mathrm{X}_{3}+0,15 \mathrm{X}_{4} \\
+0,48 \mathrm{X}_{5}+\mathrm{e}
\end{gathered}
$$

\section{Uji Koefisien Determinasi}

Pengujian koefisien determinasi dihitung menggunakan kuadrat koefisien korelasi. Adjusted $\mathrm{R}^{2}$ adalah nilai yang digunakan. Hal tersebut dikarenakan apabila menggunakan nilai $R^{2}$ hasilnya akan cenderung optimistic dalam penggambaran ketepatan regresi yang digunakan. Berdasarkan tabel 1 nilai Adjusted $\mathrm{R}^{2}$ sebesar 0,43 . Nilai tersebut berarti bahwa 43 persen variasi dari variabel terikat (keputusan pembelian) dapat dijelaskan oleh variabel bebasnya (kualitas produk, harga, kemasan, jaminan produk dan merk) sedangkan sisa dari nilai 100 persennya yaitu sebanyak 53 persen dijelaskan oleh variabel lain di luar model. 


\section{Uji-F (Simultan)}

Pengaruh apakah variabel bebas secara bersama-sama dapat mempengaruhi terhadap variabel terikat dapat dicari dengan menggunakan Uji-F (uji simultan. Berdasarkan hasil analisis yang tertera pada tabel 1 dapat dilihat nilia probabilitas $\mathrm{F}$ bernilai 0,01 (Sig 0,01<0,05), maka dapat disimpulkan bahwa variabel bebas yaitu kualitas produk, harga, kemasan, jaminan produk dan merk secara bersama sama berpengaruh terhadap keputusan pembelian produk gula kristal putih di Daerah istimewa Yogyakarta.

\section{Uji-t (Parsial)}

Salah satu pengujian statistika yang diperuntukkan untuk melihat apakah variabel independen secara parsial berpengaruh terhadap variabel dependen yaitu Uji-t (Gujarati, 2003). Berdasarkan tabel 1 dapat dilihat nilai sig-t dari masing masing variabel independen. Variabel independen yang memiliki pengaruh terhadap variabel dependen (keputusan pembelian) adalah kualitas produk dan merk $(p<\alpha)$. Kedua variabel ini memiliki pengaruh positif terhadap variabel dependen. Variabel harga, jaminan produk dan kemasan tidak memiliki pengaruh signifikan terhadap variabel terikatnya $(p>\alpha)$.

\section{Pengaruh Kualitas Produk Terhadap Keputusan Pembelian}

Berdasarkan tabel 1 dapat dilihat bahwa nilai signifikansi dari kualitas produk bernilai 0,035 sehingga dapat dikatakan bahwa nilai tersebut kurang dari 0,05 . Hasil tersebut mengindikasikan bahwa variabel kualitas produk berpengaruh signifikan terhadap keputusan pembelian produk gula kristal putih di Daerah Istimewa Yogyakarta. Sejatinya kualitas produk dibutuhkan dalam suatu bisnis dimana kepercayaan konsumen timbul apabila produk yang dihasilkan sesuai dengan keinginan konsumen. Hal tersebut membuat konsumen tidak ragu dalam membeli gula kristal putih dengan kualitas produk yang baik. Kulaitas produk dapat mengatasi keluhan konsumen secara cepat. Atas dasar hal tersebut membuat kualitas produk menjadi bahan pertimbangan konsumen melakukan keputusan pembelian (Sulasih, 2017: 43).

\section{Pengaruh Jaminan Produk Terhadap Keputusan Pembelian}

Jaminan produk yang diberikan oleh produsen atau perusahaan gula kristal putih kepada konsumen pembeli produk berupa ketahanan dan keamanan gula. Implementasi dari jaminan produk diwujudkan dalam ketersediaan tanggal kadaluarsa yang tertera dalam packaging gula kristal putih yang dijual. Atribut tersebut membuat penilaian tersendiri bagi konsumen dalam melakukan pembelian produk gula kristal putih di DIY. Dengan terteranya tangal kadaluarsa membuat konsumen percaya bahwa produk yang akan dikonsumsi aman. Berdasrkan tabel 1 dapat dilihat bahwa jaminan produk tidak berpengaruh terhadap keputusan pembelian produk gula kristal putih di DIY. Nilai signifikansi dari jaminan produk adalah 0,076 sehingga nilai tersebut lebih dari nilai alpha $(0,05)$. Hal ini dikarenakan untuk variabel jaminan produk tingkat kepekaan menjadi rendah sehingga variabel yang mempengaruhi keputusan pembelian adalah merk dan kualitas produk.

Daya tahan gula merupakan indikasi produk tahan lama untuk disimpan kemudian digunakan. Semakin lama daya tahan gula semakin tinggi pula keputusan pembelian produk gula yang dijual. Biasanya konsumen menyimpan gula kristal putih selama satu bulan lebih sehingga daya tahan gula kristal putih yang kinerjanya lebih lama akan lebih banyak dibeli oleh konsumen. Gula kristal putih yang baik biasanya memiliki daya tahan penggunaan produk kurang lebih satu tahun. Daya tahan tersebut tertera pada tanggal kadaluarsa produk gula kristal putih di kemasan produk. 


\section{Pengaruh Merk Produk Terhadap Keputusan Pembelian}

Salah satu faktor yang mempengaruhi kesetiaan konsumen terhadap suatu produk adalah merk produk. Seorang konsumen bahkan akan loyal terhadap suatu produk dan melakukan pembelian produk secara berulang karena merk produk yang sudah ternama. Merk yang sudah ternama selain itu merk yang sudah terkenal di mata konsumen akan lebih memudahkan konsumen dalam melakukan keputusan pembelian. Merk Familiar seperti gukaku, MK akan lebih mudah mendapatkan perhatian di mata konsumen dibandingkan dengan produk yang tidak terkenal. Akan tetapi perlu di garis bawahi bahwa ketika usaha untuk memperoleh produk tersebut tidak sebanding dengan manfaat yang dirasakan maka kesetiaan tersebut dapat memudar dan beralih ke produk yang lebih mudah diperoleh konsumen. Berdasarkan tabel 1 dapat dilihat bahwa nilai signifikansi dari merk produk bernilai 0,001 sehingga dapat dikatakan bahwa nilai tersebut kurang dari 0,05 . Hasil tersebut mengindikasikan bahwa variabel merk produk berpengaruh signifikan terhadap keputusan pembelian produk gula kristal putih di Daerah Istimewa Yogyakarta. Merk sering didefinisikan sebagai nama, istilah, tanda, simbol desain maupun kombinasi yang mengidentifikasikan suatu produk atau jasa yang dihasilkan oleh suatu perusahaan. Dalam kasus ini branding memberikan dampak tersendiri bagi keputusan pembelian produk oleh konsumen. Gula yang memiliki branding yang baik akan laku keras dipasaran jika dibandingkan dengan merk gula yang kurang sering di dengar maupun dilihat oleh konsumen.

\section{KESIMPULAN}

Berdasarkan hasil penelitian dapat disimpulkan bahwa ada dua faktor yang mempengaruhi keputusan pembelian produk gula kristal putih yang dilakukan oleh konsumen di Daerah Istimewa Yogyakarta yaitu kualitas produk dan merk sedangkan variabel yang tidak berpengaruh terhadap keputusan pembelian adalah harga, jaminan produk dan kemasan produk. Mengacu dari dua variabel yang berpengaruh membuat perusahaan gula kristal putih harus memilih strategi pemasaran yang tepat dalam membuat produk yang berkualitas. Tidak hanya itu saja perusahaan harus memikirkan produk yang berkualitas didampingi dengan jaminan produk yang baik disertai merk dan branding produk yang baik pula.

\section{DAFTAR PUSTAKA}

Agung, Silih Wasesa, Jim Macnamara. 2006. Strategi Public Relations. Jakarta: PT Gramedia.

Aaker, D. (2011). Brand Relevance: Making Competitors Irrelevant. San Fransisco: Jossey Bas

Darmawan, G.S. (2018). The Influence of Service Quality Towards Customer Loyalty Through Corporate Image and Costumer Satisfaction (Study on PT BRI (Persero) Tbk. Bantur Unit Customers). Jurnal Referensi: IImu Manajemen dan Akutansi. 6(1), 91105.

Direktoral Jendral Perkebunan. 2015. Statistik Perkebunan Indonesia 20152017 (Tebu). Direktoral Jendral Perkebunan. (Diakses 18 Februari 2020).

Engel, J.F., D.B. Roger, dan W.M. Paul.1994b. Perilaku Konsumen. Edisi keenam. Jilid 2. Binapura Aksara. Jakarta

Faullant, R., Matzler, K., dan Fuller, J. (2008), The Impact of Satisfaction and Image on Loyalty: The Case of Alpine Ski Resorts, Managing Service Quality, Vol. 18, No. 2, hal. 163-178.

Gujarati, Damodar, 1999, Ekonometrika Dasar, Erlangga, Jakarta.

$\begin{array}{ccc}\text { Gunawan, C.I. } & \text { (2016). } & \text { Strategi } \\ \text { Pengembangan } & \text { Ekonomi } & \text { Sumber }\end{array}$ 
Daya Manusia: Dampak Pengurangan Tenaga Kerja Migran Sektor Informal. Jurnal Referensi: IImu Manajemen \& Akutansi, 7 (1).

Kotler, P. 2005. Manajemen Pemasaran. Edisi kesebelas. Jilid 1. Indeks. Jakarta

Kotler, Philip dan Keller Kevin Lane. 2008. Manajemen Pemasaran. Edisi 13. Jilid 2. Jakarta : Erlangga.

Kurniasari, Annisa. 2013. Pengaruh Citra Merek Dan Keluarga Terhadap Keputusan Pembelian Honda Beat,Vol.1 Nomor 1, Januari 2013. Jurnal IImu Manajemen. Jurusan Manajemen, Fakultas Ekonomi, Univsitas Negeri Surabaya, Kampus Ketintang Surabaya 60231.

Kusumowardhani, RAj. Harisudin, M. Ani, SW. 2019. Analisis Kepuasan Konsumen Terhadap Produk Cokelat Monggo di Kotagede, Daerah Istimewa Yogyakarta. Agrisaintifika Jurnal IImuilmu Pertanian. Vol 8 (2). 134-140

Nasir, Akhmad. 2017. The Influence of Product Innovation Toward Marketing Performance at Furniture Companies in Pasuruan Regency. Jurnal IImu Manajemen dan Akuntansi. Vol 5 (1). 20-25

Nasir, Akhmad. 2018. Pengaruh Inovasi Produk Terhadap Kinerja Pemasaran Industri Mebel di Kabupaten Pasuruan. Jurnal IImu Manajemen dan Akuntansi.Vol 6 (2). 17-23

Novitawati, RKD. Mahfud, A. Sasongko T. 2019. Pengaruh Kualitas Produk dan Harga Terhadap Loyalitas Pelanggan Pada Sanger Warung Kopi Aceh Kota Malang. Jurnal IImu Manajemen dan Akuntansi. Vol 7 (2). 130-136.
Rahareng, VJ. Relawan IN. 2017. Pengaruh Kualitas Pelayanan Akademik Terhadap Kepuasan Mahasiswa. Jurnal Ilmu Manajemen dan Akuntansi. Vol 5 (1). 46-54

Rohman, A. (2018). Kepemimpinan Pelayanan Prima di Pedesaan. Jurnal Reformasi, 7 (1).

Sugiono. 2007. Statistika Untuk Penelitian, Alfabeta, Bandung.

Sulasih. (2017). A Study of Price Perception, Packaging, and Service Quality Towards Consymers' Interest in Purchasing Special Product of Bumiayu, Central Java. Jurnal Referensi: IImu Manajemen dan Akutansi. 5(1), 38-45.

Susanto, R.Y. (2017). Studi tentang Pengelolaan Pasar Tradisional pada Pasar Blimbing Kota Malang. Jurnal Referensi: IImu Manajemen dan Akutansi. 5(2), 1-10.

Tjiptono, F. 1995. Strategi Pemasaran. Andi Offset. Yogyakarta.

Tjiptono, Fandy.2011, Pemasaran Jasa. Bayumedia, Malang.

Walpole, R.E. 1992. Pengantar Satistik Edisi ke-3. PT. Gramedia Pustaka Utama. Jakarta

Wisudawati, T. Dharmistiti, R. 2018. Evaluasi Kepuasan Layanan Pada Gerbong Khusus Wanita Kereta Prambanan Ekspress (Prameks) Dengan Servqual. UMS : Seminar Nasional IEANACO

Wisudawati, T. Sulistyowati, E. 2019. Penerapan Metode Marketing Mix 7P Untuk Strategi Pemasaran Produk Daur Ulang. UPN Yk: Prosiding Industrial Enginering Conference (IEC) 